\title{
Microparticles for delivering therapeutic peptides and proteins to the lumen of the small intestine
}

\author{
Maria João Lopes Gonçalves de Brito Amorim, João Paulo Medeiros Ferreira* \\ Escola Superior de Biotecnologia, Universidade Católica Portuguesa, Porto, Portugal
}

Keywords: Microparticles; Emulsion/solvent evaporation technique; Enteric forms; Protein stability; Proteolytic degradation; Inflammatory conditions of the intestines

\begin{abstract}
Several different peptides and proteins, such as the pancreatic trypsin inhibitor, growth factors and trefoil peptides, are known to play important roles in maintaining the structure and function of the gastrointestinal wall. With the advent of recombinant biotechnology, it has become feasible to test some of these proteins as therapeutics in different inflammatory conditions of the intestines. However, the harsh $\mathrm{pH}$ and enzymatic conditions of the stomach can lead to their inactivation. This research was aimed at the development of particulate, gastricresistant pharmaceutical forms, incorporating those bioactive molecules. Mixtures of proteins in powder form were coated with cellulose acetate phthalate, Eudragit ${ }^{\circledR}$ S100 or Eudragit ${ }^{\circledR}$ RS PO, using simple preparation techniques based on single emulsion/solvent evaporation. Using aprotinin as a model drug, it was found that these procedures were effective in microencapsulating protein in the solid form without affecting its biological activity. Furthermore, and in particular with the first two polymers above, particles showed adequate in vitro release patterns for the applications envisioned. (c) 2001 Elsevier Science B.V. All rights reserved.
\end{abstract}

\section{Introduction}

Different inflammatory conditions of the gastrointestinal (GI) tract are among the most common clinical situations. Diseases of this type include gastric and duodenal ulcers, ulcerative colitis, or Crohn's disease [1]. In all of these conditions, the mechanisms of mucosal homeostasis have become impaired.

The normal structure and functioning of the GI epithelia are guaranteed, among others, by the action of over 20 different peptides and small molecular weight (MW) proteins, such as transforming growth factors, trefoil peptides, epidermal growth factor, and pancreatic secretory trypsin inhibitor [1]. Advances in biotechnology have lead to the availability of some synthetic and recombinant forms of these proteins and peptides. One may consider, then, the administration of these molecules in therapies of the above pathologies $[2,3]$. Due to their luminal action, oral administration can be adequate and convenient. However, the stress conditions of the GI, such as the low $\mathrm{pH}$ in the

\footnotetext{
* Corresponding author. Escola Superior de Biotecnologia, U.C.P., Rua Dr António Bernardino de Almeida, 4200-072 Porto, Portugal. Tel.: +35122-5580027; fax: +351-22-5090351.

E-mail address: jpf@esb.ucp.pt (J.P.M. Ferreira).
}

stomach and the proteolytic activities in both the stomach and the small intestine, may lead to their early and irreversible inactivation [4-6]. So, adequate pharmaceutical forms, that protect those proteins and release them at the damaged sites, are to be developed and tested.

Particulate pharmaceutical forms have shown several advantages over other forms, such as more uniform transit times through the GI tract, less variability among individuals, and a smaller risk of dose dumping and high local concentrations.

In this study, trypsin inhibitor from bovine lung, aprotinin (Apro), was selected as the model drug. This molecule is similar to the trypsin inhibitor produced in the pancreas, which protects the organ from damage by prematurely activated proteases, or produced in various other tissues, such as the foveolar cells of the GI lining, that protect the mucus layer from excessive digestion [1].

As the concentrations of the Apro needed at the mucosal surface are quite small, the formulations developed also include a bulking agent, in this case, casein from bovine milk. This selection was based on previous studies which showed that casein can protect other proteins from the action of pancreatic enzymes [5,6].

Among the coating materials that looked adequate for this application, the polymers cellulose acetate phthalate (CAP), 
and the polyacrylates Eudragit ${ }^{\circledR}$ S100 (E S100) and Eudragit ${ }^{\circledR}$ RS PO (E RSPO) were selected. The first two materials are gastro-resistant, and become soluble at neutral and alkaline pHs; the third one is insoluble in water and digestive juices, but it is permeable and swells in solution. Among the various alternative methods to produce small coated particles, techniques of emulsion/solvent evaporation were employed.

\section{Materials and methods}

\subsection{Materials}

These included: CAP (Schultz \& Co., Germany); Eudragit $^{\circledR}$ RS PO (E RSPO), Eudragit ${ }^{\circledR}$ S100 (E S100; Rohm Pharma, Germany); technical grade casein from bovine milk, trypsin, benzoyl-DL-arginine- $p$-nitroanilide (BAPNA), Apro from bovine lung, Span 80, magnesium stearate (Sigma Chemicals, St. Louis, MO); silicon antifoaming, cyclohexane, ethyl ether (Merck KGaA, Germany); acetone, liquid paraffin and ethyl alcohol (José Vaz Pereira, Portugal).

\subsection{Preparation of core materials}

Core material was constituted by a bulking agent, casein from bovine milk, with or without the model drug Apro incorporated. Bulking agent and Apro powders, at 100:1300:1 weight ratios, were simply mixed thoroughly. The particle sizes of the powders were within the range of 250-500 $\mu \mathrm{m}$.

\subsection{Preparation of microcapsules}

CAP microparticles were prepared by a simple emulsion, solvent evaporation method, based on the ones reported by Silva and Ferreira [7]. The polymer was dissolved in 10:1 mixtures $(20 \mathrm{ml})$ of acetone/98\% ethanol, at a 5-10\% (w/v) concentration. Variable amounts of core material, in the powder form, were dispersed in this solution by magnetic stirring. Liquid paraffin $(120 \mathrm{ml})$ containing $1 \%(\mathrm{w} / \mathrm{v})$ Span 80 was then placed in a $400 \mathrm{ml}$ beaker, and agitated at 450 revs./min with a three-bladed propeller stirrer (diameter, 5 $\mathrm{cm}$ ) linked to a stirring motor (Tecmatic SD2). The above dispersion was then poured into the paraffin. The solvent was evaporated at room temperature for 5-7 h. The microcapsules were collected in a Buchener filter, washed 2-3 times with ethyl ether, and dried at room temperature for $24 \mathrm{~h}$.

E RSPO ( $2.5 \mathrm{~g})$, followed by $0.15 \mathrm{~g}$ magnesium stearate, was dissolved in $30 \mathrm{ml}$ acetone, and then $0.5-1.5 \mathrm{~g}$ of protein powder was dispersed in the solution. The suspension was added to $150 \mathrm{ml}$ paraffin containing $0.5 \mathrm{ml}$ Span 80 , as above. Solvent evaporation took, on average, $4 \mathrm{~h}$. Microcapsules were recovered by filtration, washed with cyclohexane, and dried as before. This corresponds to a modification of the techniques reported by Goto et al. [8].

The procedure for preparing the E S100 particles was based on the one employed by Lorenzo-Lamosa et al. [9]. The polymer $(2 \mathrm{~g})$ was dissolved in $30 \mathrm{ml}$ of acetone/ethanol $(2: 1, \mathrm{v} / \mathrm{v})$. Casein or core powder mixture $(1-4 \mathrm{~g})$ was dispersed in the polymer solution, and the suspension was then dispersed in $100 \mathrm{ml}$ liquid paraffin containing $1 \%(\mathrm{v} / \mathrm{v})$ Span 80 and $0.1 \%$ (v/v) silicon antifoaming. The remaining steps were as in the previous protocol, but total evaporation of the solvent took, in this case, 15-17 h.

\subsection{Particle sizing and morphological characterization of the particles}

Particle size distributions were carried out by sieving analysis, using a series of laboratorial sieves with apertures between $125-1800 \mu \mathrm{m}$.

Examination of the surface morphology and crosssections of the microparticles were performed by scanning electron microscopy (SEM; Jeol, JSM - 5600 LV Scanning Electron Microscope). The microparticles had no special treatment for SEM analysis and were cross-sectioned by pressure with a sharp scalpel.

\subsection{Release studies}

Release studies of the proteins from the microcapsules were performed under sink conditions, in sealed plastic tubes immersed in a water bath (JULABO, SW-20C, Portugal), with the temperature maintained at $37^{\circ} \mathrm{C}$, and agitated at $100 \mathrm{revs} . / \mathrm{min}$. For the first $2 \mathrm{~h}$, microcapsules $(\sim 100 \mathrm{mg})$ were suspended in $20 \mathrm{ml}$ of $0.1 \mathrm{M} \mathrm{HCl}$, then this solution was decanted and replaced with $0.1 \mathrm{M} \mathrm{HCl} / 2 \mathrm{M} \mathrm{Na}_{3} \mathrm{PO}_{4}(\mathrm{pH}$ $6.8)$. Samples $(1 \mathrm{ml})$ were removed at appropriate time intervals, and passed through $45 \mu \mathrm{m}$ filters.

\subsection{Determination of total protein and Apro contents}

Total protein determinations were carried out by the Lowry method, using a calibration curve obtained with a standard solution of casein. Apro in solution was quantified by a trypsin inhibition assay, that uses BAPNA as a substrate [10], and using calibration curves obtained with the same chemicals and reaction conditions. The validity of the method for the different conditions employed was always verified.

\section{Results and discussion}

\subsection{Particle morphology}

Fig. 1A illustrates size distributions for particles coated with CAP, at two different polymer/core ratios (1:3 and $1: 1.7, \mathrm{~g} / \mathrm{g}$ ). In both cases, more than $90 \%$ (weight $\%$ ) were in the range of $0.5-2 \mathrm{~mm}$, with mean particle diameters of 1-1.2 mm. Regarding the acrylate particles, Fig. 1B shows 

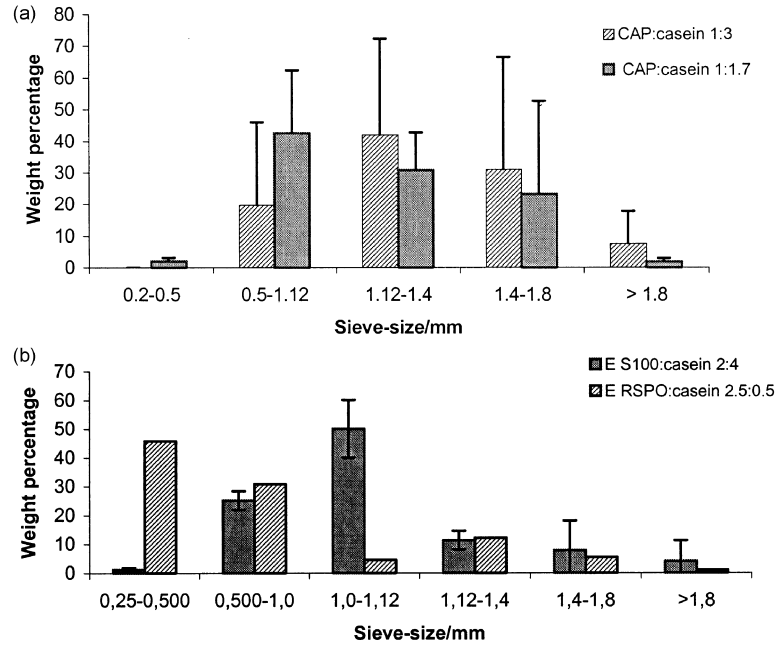

Fig. 1. (A) Size distributions for microcapsules of casein coated with CAP, as determined by sieving analysis. Values are averages \pm SD of three batches, in each case. (B) Size distributions for microcapsules of casein coated with E RSPO or E S100, as determined by sieving analysis. The values for E S100 particles are averages \pm SD of three batches, and those for E RSPO particles are of a single representative batch.

that the E S100 microcapsules were in the same size range as the CAP ones, but the E RSPO particles had a smaller mean particle diameter. Although only one batch is illustrated in Fig. 1B for E RSPO, three other batches were sized with a different set of sieves, with identical conclusions. Nevertheless, it should be mentioned that, despite careful control of experimental variables, such as the stirring rate and temperature of solutions, particles of repetitive batches sometimes did not exhibit very reproducible size distributions.

The particles were regularly shaped (Fig. 2), with a more or less pronounced porous structure. SEM suggested that the E RSPO capsules were the least porous. Regarding the dispersion of the core material, their morphologies correspond to either the reservoir type, with single or multiple powder cores, or to the monolithic structure. A more definite conclusion is difficult to reach with this procedure, as powder leakage may occur when preparing the particles for the cross-sectional views.

\subsection{Microencapsulation yields}

The overall yields of the procedures were evaluated by comparing the initial weight of polymer plus core material with that of the recovered, dried microparticles. The protein yields take into account only the protein content of the particles, as determined by complete dissolution studies. Table 1 lists the values of these parameters for the CAPcoated particles, at different initial weights of CAP and casein. Protein yields were above 50\%, and overall process yields were above $80 \%$, in all but one case. At low CAP/ casein ratios, these parameters were both above $90 \%$.

Table 2 lists the same parameters for the E RSPO and E
S100 particles. For the former, and at the high polymer/core ratio of 2.5:0.5, an average of $76 \%$ of the protein was encapsulated, but the overall yield was only $17 \%$. This value is explained by the presence of polymer in excess, that was observed to deposit on the propeller and, to a lower extent, on the vessel wall during the preparation. At a 2:1 ratio, the yields were significantly higher. With E S100, on the other hand, the protein was totally recovered in the particles, and excess of polymer occurred at ratios above 2:1 (g/g; data not shown).

\subsection{Release studies}

In order to simulate conditions through the GI tract, the microparticles were incubated for $2 \mathrm{~h}$ in acidic medium, followed by incubation in a phosphate buffer at neutral $\mathrm{pH}$. Due to the high dilution of Apro in the powder mixtures with casein, the release of total protein (essentially casein) and that of Apro were measured separately, by distinct procedures. For Apro, an enzymatic method was used, which is more relevant than just peptide content, as any biological deactivation during particle preparation would be evaluated as well.

Fig. 3 shows the release profiles for casein (total protein) from particles coated with CAP, at different weight ratios of the two materials. In all experiments, no release of protein was observed in $\mathrm{HCl}$ medium. After transferring to $\mathrm{pH} 6.8$ buffer, the casein content in solution increased progressively, for approximately $3 \mathrm{~h}$. There were no significant differences in the release rates or in the time for total release among particles prepared with different amounts of CAP and casein (Fig. 3).

The release of Apro was followed for the particles with a $\mathrm{CAP} /$ casein ratio of $1: 3$, which were selected due to their higher yields. Fig. 4 shows that, in acidic medium, the Apro was retained in the particles to a great extent. After placing them in phosphate solution, over $90 \%$ of the Apro content was released in just half an hour. For comparison, Fig. 4 includes the release of casein.

The total protein release from the particles prepared with the two Eudragit types can be seen in Fig. 5. The release profiles of casein from different E RSPO particles were similar, and slightly faster than the release from the E S100 ones. Analogous observation holds for the release of Apro (Fig. 6). However, while casein was completely retained in the particles in acidic medium, for Apro, some leaching was observed. During the $2 \mathrm{~h}$ incubation period, the E RSPO particles lost approximately half of the Apro, but the E S100 ones released only $20 \%$, a value similar to the CAP particles. The results with E RSPO are not surprising, since this polymer is not designed for enteric forms. Once in solution, it becomes slightly permeable and swells, therefore with increased pore size. Also, the smaller size of these particles (Fig. 1) may result in shorter release times.

The faster release of Apro, compared with that of casein, in phosphate buffer, is due to one or both of the following 


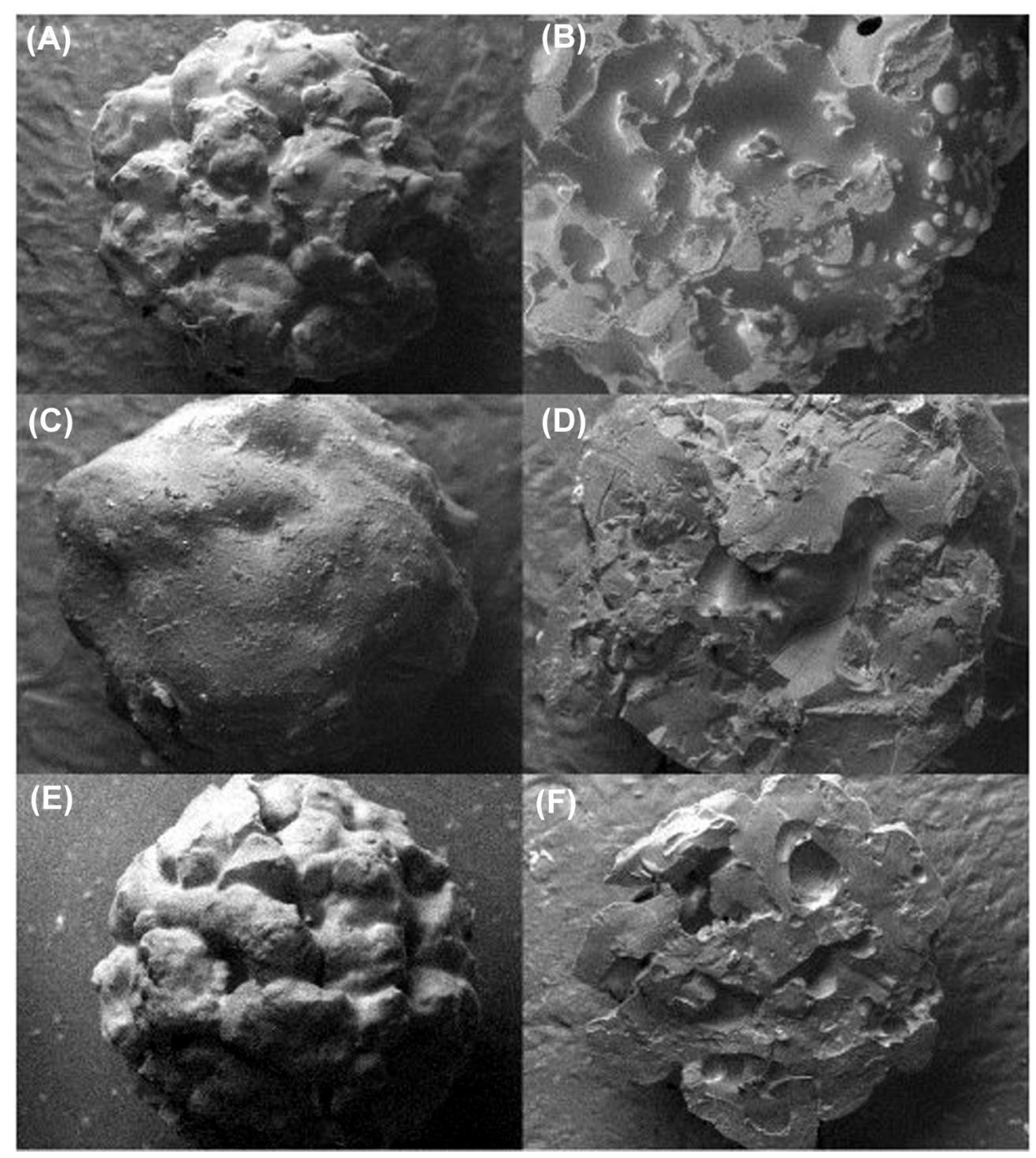

Fig. 2. Scanning electron micrographs for microparticles of CAP, E RSPO and E S100. The voltage applied was $20 \mathrm{kV}$. Bars correspond to $100 \mu \mathrm{m}$ : (A), $75 \times$ resolution; and (B), $100 \times$ resolution of microcapsules CAP/casein, 1:3. (C) 100×; and (D), 100× resolution of microcapsules E RSPO/casein, 2.5:0.5. (E) $90 \times$; and (F), $85 \times$ resolution of microcapsules E S100/casein, 1:2. (A), (C) and (D) are entire particles, while (B), (D) and (F) are cross-sectional views.

factors. When the capsules are changed to this medium, the Apro is already hydrated, while the casein powder has to initiate its dissolution. The smaller size of Apro (MW, 6

Table 1

Yield determinations of casein microcapsules coated with $\mathrm{CAP}^{\mathrm{a}}$

\begin{tabular}{lll}
\hline CAP/casein weight $(\mathrm{g} / \mathrm{g})$ & $\begin{array}{l}\text { Overall } \\
\text { microencapsulation } \\
\text { efficiency }(\%)\end{array}$ & $\begin{array}{l}\text { Protein } \\
\text { microencapsulation } \\
\text { efficiency }(\%)\end{array}$ \\
\hline $2: 1.0(n=3)$ & 79 & 55 \\
$2: 2.0(n=2)$ & 72 & 70 \\
$1: 1.0(n=2)$ & 86 & 52 \\
$1: 1.7(n=3)$ & 94 & 90 \\
$1: 3.0(n=3)$ & 97 & 96 \\
\hline
\end{tabular}

${ }^{a}$ Values are averages of $n$ batches, differing by no more than $10 \%$.
$\mathrm{kDa}$ ) enables it to diffuse out from the polymer structure (Fig. 2) faster or earlier than casein. The influence of the MW in the release pattern was also observed in microcap-

Table 2

Yield determinations of casein microcapsules coated with E RSPO and E $\mathrm{S} 100^{\mathrm{a}}$

\begin{tabular}{llll}
\hline Eudragit type & $\begin{array}{l}\text { Eudragit/casein } \\
\text { weight }(\mathrm{g} / \mathrm{g})\end{array}$ & $\begin{array}{l}\text { Overall } \\
\text { microencapsulation } \\
\text { efficiency (\%) }\end{array}$ & $\begin{array}{l}\text { Protein } \\
\text { microencapsulation } \\
\text { efficiency }(\%)\end{array}$ \\
\hline RSPO $(n=4)$ & $2.5: 0.5$ & 17 & 76 \\
RSPO $(n=2)$ & $2: 1$ & 53 & 94 \\
S100 $(n=3)$ & $2: 4$ & 98.5 & 98.5 \\
\hline
\end{tabular}

\footnotetext{
${ }^{\text {a }}$ Values are averages of $n$ batches, differing by no more than $10 \%$.
} 


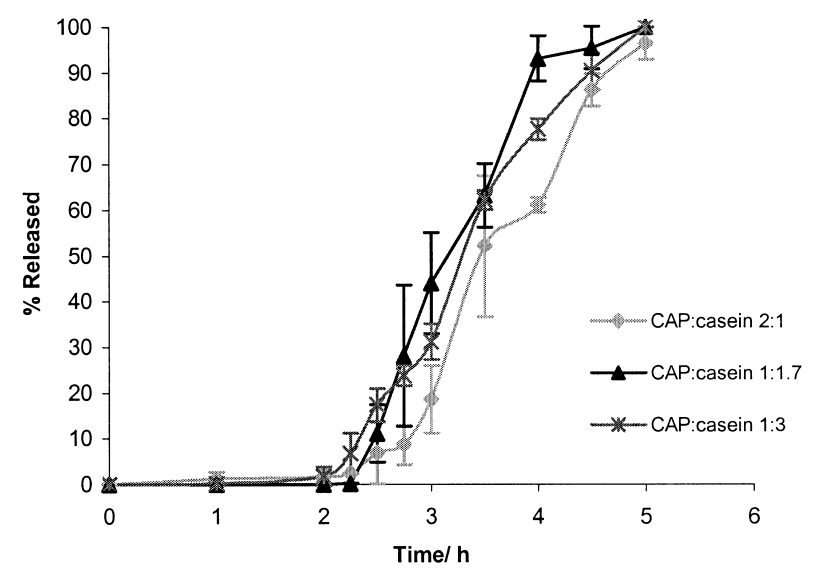

Fig. 3. Release of protein for CAP/casein microcapsules, as measured by the Lowry method. Results are averages \pm SD of three independent batches, in each case.

sules containing casein hydrolysate as the major core material, instead of casein. That hydrolysate contains mainly single amino acids, with a few percent of short oligopeptides. In this case, the hydrolysate was totally and quickly released in $\mathrm{HCl}$ medium, while the Apro was retained to a great extent (data not shown). These results, as regards CAP microcapsules in acidic solution, are also in agreement with previous ones for non-protein drugs [7], that showed that low MW molecules leach from the particles, while larger ones are retained by the polymeric structure.

We note that samples of hydrochloric acid solutions were evaluated for Apro bioactivity soon after being collected,

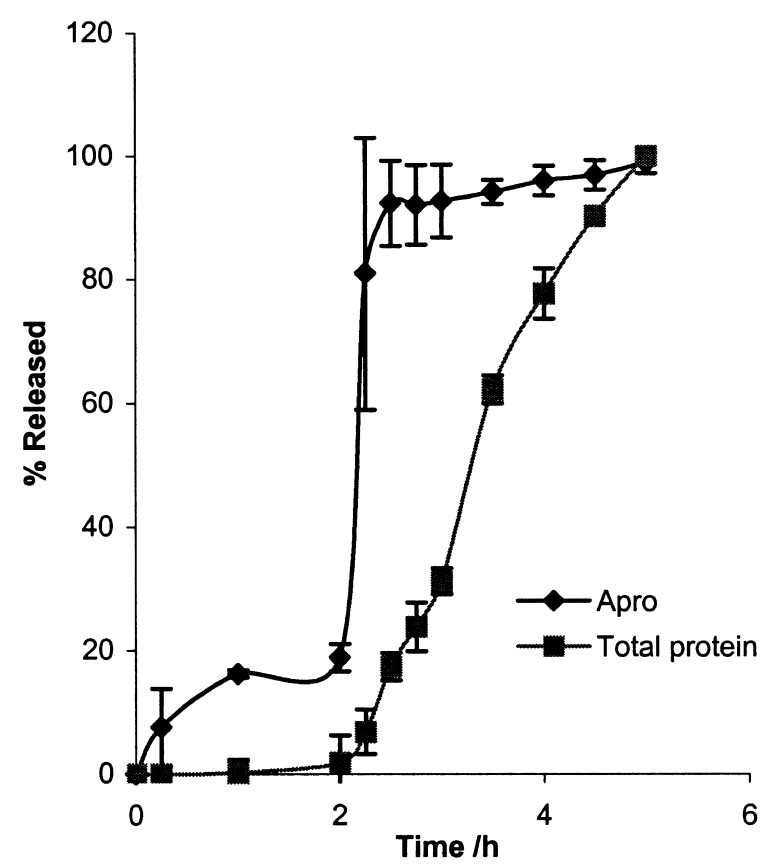

Fig. 4. Comparison between release of total protein (as measured by the Lowry method), and release of Apro (as measured by the enzymatic assay) for microcapsules $\mathrm{CAP} /$ protein at $1: 3$ ratio. Results are averages $\pm \mathrm{SD}$ of three independent batches.

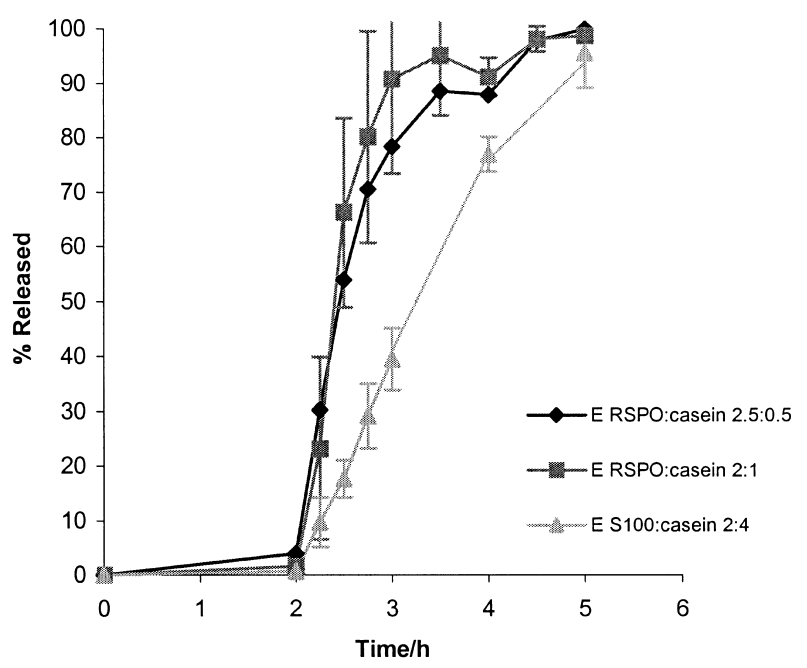

Fig. 5. Release of protein for microcapsules of E RSPO and E S100. The values for $\mathrm{E}$ RSPO/casein 2.5:0.5 and for E S100/casein 2:4 are averages \pm $\mathrm{SD}$ of three batches, and those for E RSPO/casein 2:1 are averages of two batches.

but that Apro is particularly resistant to inactivation by low $\mathrm{pH}$ environments. No loss of activity was observed after a $48 \mathrm{~h}$ incubation in $0.1 \mathrm{M} \mathrm{HCl}$ solution. However, with other proteins, different protocols for evaluating release and bioactivity in simulated gastric media might need to be adopted.

\section{Conclusions}

In this work, it was found that the single emulsion/solvent evaporation methods employed were adequate for microen-

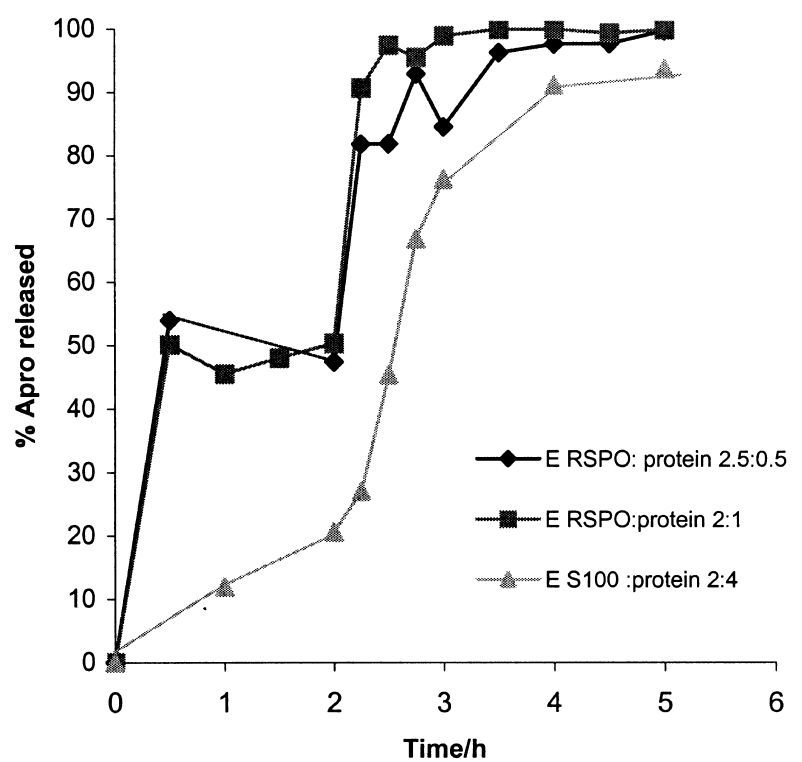

Fig. 6. Release of Apro for microcapsules coated with E RSPO and E S100. The values for E RSPO/protein 2:1 and E S100/protein 2:4 are averages of two batches, while those for E RSPO/protein 2.5:0.5 are averages of three batches. 
capsulating casein and Apro in the powder forms. Also, the biological activity of Apro was not affected.

Both CAP and E S100 microcapsules represent interesting forms for delivering small MW proteins, such as Apro, to the intestine, avoiding exposure to gastric conditions. However, with CAP particles, release of the active agents can take place in a proximal part of the intestine, while the release can be delayed to lower parts of the intestine with $\mathrm{E}$ S100 ones. In vivo studies will elucidate the potential of these forms in dealing with the extremely common, diverse, and therapeutically challenging conditions of inflammation of the intestines.

\section{Acknowledgements}

This work was supported by the grant PRAXIS XXI, PCNA/C/BIO/66/96, from Fundação da Ciência e Tecnologia, Portugal.

\section{References}

[1] R.J. Playford, C. Shaw-Smith, Growth factors and ulcerative gastrointestinal disease, Balliere's Clin. Gastroenterol. 10 (1996) 135-149.
[2] A. Guglietta, P.B. Sullivan, Clinical applications of epidermal growth factor, Eur. J. Gastroenterol. Hepatol. 7 (1995) 945-950.

[3] W. Haedo, T. González, J.A. Más, S. Franco, B. Gra, G. Soto, A. Alonso, P. López-Saura, Oral human recombinant epidermal growth factor in the treatment of patients with duodenal ulcer, Rev. Esp. Enferm. Dig. 88 (1996) 409-413.

[4] F. Araki, H. Nakamura, N. Nojima, K. Tsukumo, S. Sakamoto, Stability of recombinant human epidermal growth-factor in various solutions, Chem. Pharm. Bull. 37 (1989) 404-406.

[5] R.J. Playford, A.C. Woodman, P. Clark, P. Watanapa, D. Vesey, P.H. Deprez, R.C.N. Williamson, J. Calam, Efffect of luminal growth factor preservation on intestinal growth, Lancet 341 (1993) 843-848.

[6] R.J. Playford, T. Marchbank, D.P. Calnan, J. Calam, P. Royston, J.J. Batten, H.F. Hansen, Epidermal growth factor is digested to smaller, less active forms in acid gastric juice, Gastroenterology 108 (1995) 92-101.

[7] J.P.S. Silva, J.P.M. Ferreira, Effect of drug properties on the release from CAP microspheres prepared by a solvent evaporation method, J. Microencapsul. 16 (1999) 95-103.

[8] S. Goto, M. Kawata, M. Nakamura, Y. Nagatsuma, K. Fujinaga, T. Aoyama, Evaluation of sustained release properties of Eudragit RS, RL and S (acrylic resins) microcapsules containing ketoprofen in beagle dogs, J. Microencapsul. 5 (1988) 343-360.

[9] M.L. Lorenzo-Lamosa, C. Remuñán-Lopez, J.L. Vila-Jato, M.J. Alonso, Design of microencapsulated chitosan microspheres for colonic drug delivery, J. Controlled Release 52 (1988) 109-118.

[10] D.C. Egberg, R.H. Potter, G.R. Honold, The semiautomatic determination of trypsin inhibitors in textured soy protein, J. Agric. Food Chem. 23 (1975) 603-605. 